\title{
Early adoption protects against internalizing, but not externalizing, problems
}

\author{
By Jessica K. Edwards
}

The effects of childhood adoption on adult outcomes are conflicting; the adoption of children from highrisk backgrounds can have protective effects, as evidenced by generally positive cognitive skills and school achievements. ${ }^{1}$ However, adopted children can show increased vulnerability to mental health problems during childhood and adulthood. ${ }^{2,3}$ This increased vulnerability might be due to experiencing adverse life events prior to adoption or to problems in the postadoption home environment. Now, researchers in the UK have used data from two groups of early-adopted individuals (from the 1958 and 1970 British birth cohorts) to comprehensively describe outcomes up to mid-life. They compared them with the outcomes of children who were raised with two biological parents (a "general population" group) and also to children who were born to single mothers but were not adopted (a "birth comparison" group). The adopted children shared similar early characteristics with the birth comparison group but were placed in more socially advantaged adoptive homes.
The researchers found few differences between the adopted groups and the general population group in terms of physical health and psychological well-being, but more favourable outcomes in these domains compared to the birth comparison group. The rates of adult externalizing behaviours (including adult convictions, smoking and problem drinking) in the adopted and birth comparison groups, however, were higher compared to the rates in the general population group. These data suggest that although adoption can have protective effects in terms of internalizing problems, it might not be protective in relation to externalizing problems. The data from this study suggested that prenatal adversity might contribute to these externalizing problems. However, more work is needed to better understand the early and late experiences that contribute to this more negative trajectory in at-risk children. 


\section{Referring to:}

Sehmi, R., Rushton, A., Pickles, A., Grant, M. \& Maughan, B. (2020), Infant domestic adoption: outcomes at mid-life. J. Child Psychol. Psychiatry. doi: 10.111/jcpp.13178.

\section{References:}

${ }^{1}$ van ljzendoorn, M.H. et al. (2005), Adoption is a successful natural intervention enhancing adopted children's IQ and school performance. Curr. Dir. Psychol. Sci. 14,: 326-330. doi: 10.1111/j.09637214.2005.00391.x.

${ }^{2}$ Juffer, F. et al. (2005), Behaviour problems and mental health referrals of international adoptees - A meta-analysis. JAMA. 293: 2501-2515. doi: 10.1001/jama.293.20.2501.

${ }^{3}$ Behle, A.E. et al. (2016), Psychiatric disorders and treatment in adoptees: A meta-analytic comparison with non-adoptees. Adopt. Q. 19: 284-306. doi: 10.1080/10926755.2016.1201708.

\section{Glossary:}

Internalizing problems: individuals with internalizing problems typically attempt to conceal their maladaptive emotions and cognitions. This internalizing approach can manifest as depression, withdrawal, low self-esteem, anxiety and/or loneliness. Some affected individuals might also exhibit suicidal behaviours.

Externalizing problems: individuals with externalizing problems exhibit their maladaptive thoughts and emotions externally. Characteristic behaviours include impulsivity, and antisocial or aggressive behaviours. Adult manifestations of externalizing problems can include alcohol-related or substance-related disorders. 